\title{
Post-transplantation morphological and functional changes in kidneys from expanded criteria donors
}

\author{
B Borda ${ }^{1}$, T Németh ${ }^{1}$, A Ottlakan ${ }^{1}$, C Keresztes ${ }^{2}$, É Kemény ${ }^{3}$, G Lázár ${ }^{1}$ \\ ${ }^{1}$ Faculty of Medicine, Department of Surgery, University of Szeged, Szeged, Hungary \\ ${ }^{2}$ Department for Medical Translation and Communication, University of Szeged, Szeged, Hungary \\ ${ }^{3}$ Faculty of Medicine, Institute of Pathology, University of Szeged, Szeged, Hungary
}

Received: October 3, 2016

Accepted: October 30, 2017

\begin{abstract}
Introduction: Despite an increase in the number of cadaver donors and overall organ transplantations, the dramatic increase in the waiting list makes it necessary to reconsider donor criteria. The authors wanted to examine whether differences could exist in the function and/or morphology of transplanted kidneys originated from expanded criteria donors (ECDs) and ideal donors 1 and 5 years after transplantation. Methods: Kidney function and histopathologic findings were analyzed and compared 1 and 5 years after transplantation in 97 patients having ECD kidneys and in 178 patients who received ideal donor kidneys (IDK). Results: Serum creatinine level was significantly higher $(p=0.001)$ and estimated glomerular filtration rate was significantly lower $(p=0.003)$ in patients having ECD kidneys as compared with those with IDK 5 years after transplantation. Morphological changes in the transplanted kidneys, such as tubulitis $(p=0.025)$ and interstitial inflammation $(p=0.002)$, were significantly more frequently present in patients with ECD kidneys than in those with IDK 1 year after transplantation. Conclusion: Despite an absence of differences in kidney function 1 year after kidney transplantation between patients having ECD and IDK, morphological differences in the transplanted kidneys can be detected between the two groups of patients.
\end{abstract}

Keywords: expanded criteria donor kidney, ideal donor kidney, kidney transplantation, Banff score

\section{Introduction}

The incidence of end-stage renal failure is growing all over the world $(4,14)$. Two treatment options are available: dialysis and kidney transplantation. Kidney transplantation provides improved quality of life and long-term survival compared with dialyzed patients. Due to the gradual increase in the number of patients on the transplant waiting list, expanding the criteria regarding donors is required. Although most studies of expanded criteria donor (ECD) kidney transplantation confirm lower allograft survival rates and, generally, worse outcomes than standard criteria donor kidneys, recipients of ECD kidneys generally have improved survival compared with wait-listed dialysis patients, thus encouraging the pursuit of this type of kidney transplantation.

There are ECD kidneys and ideal donor kidneys (IDK) in accordance with donor criteria (9). The incidence of transplantation from older donors ( $>50$ years of age) was $12.5 \%$ in 1995 , this ratio increased to $25.3 \%$ in 2005 in Hungary $(8,10)$. Although there is no clear consensus regarding the definition of ECDs and IDK, in case of donors above the

\footnotetext{
Corresponding author: Bernadett Borda, $\mathrm{MD}, \mathrm{PhD}$

Department of Surgery, University of Szeged

Semmelweis u.8., Szeged H-6720, Hungary

Phone/Fax: +36 62545 462; E-mail: borda.bernadett@med.u-szeged.hu
} 
age of 55 years, non-heart-beating donation (NHBD), cold ischemia time (CIT) above $36 \mathrm{~h}$ and donors having diabetes mellitus or hypertension for more than 10 years, the kidney is considered to be ECD kidney $(8,13)$. International studies found that ECD kidneys were not significantly worse compared with IDK after the transplantation $(7,17)$. Compared with dialysis, transplantation with ECD kidney is more cost-effective results in better quality of life and long-term survival, therefore, expanding donor criteria is indicated $(8,18)$.

The aim of this study was to evaluate the survival as well as functional and histopathological changes of ECDs and IDK. In accordance with previous studies, survival of "optimal" donor grafts was better compared with that of ECD kidneys, although it is less established whether there is any difference regarding function and/or morphology of ECDs and IDK 1 and 5 years after the transplantation.

\section{Methods}

In the Department of Surgery, University of Szeged, 275 patients were transplanted between January 1, 2010 and December 31, 2015. About 97 kidneys were obtained from ECDs and 178 kidneys were IDK. NHBD was performed in two cases, CIT was more than $36 \mathrm{~h}$ in eight cases, the donors had hypertension in 27 cases, and the donors were above the age of 55 in 60 cases in the ECD groups.

In this study, the gender and serum creatinine levels of the donors, the perfusion solution, diuresis for $24 \mathrm{~h}$ before the removal of the organ, CIT, incidence of human leukocyte antigen (HLA)-mismatch, cause of death of the donor, and the age of the donor were examined. Functional and histopathological changes in the kidneys were examined 1 and 5 years after the transplantation in the two patient groups. Estimated glomerular filtration rate (eGFR) was calculated using the Cockroft-Gault formula.

Histopathological changes of the graft were examined 1 year after the transplantation in 275 patients with kidney biopsy performed in accordance with protocol. Biopsy was performed in case of all kidneys before the transplantation. Histological sample was collected with a $16 \mathrm{G}$ tru-cut-type needle. Sections were evaluated after standard histological staining (hematoxylin and eosin, periodic acid Schiff, trichrome, and methenamine silver) using a light microscope. Immunohistochemistry tests were performed with the identification of anti-HLA class II antibodies, complement 4d (C4d), C3, IgG, IgA, and IgM. Histological changes were classified using the Banff score from Loupy et al. and Banff Working Groups $(5,11)$.

The study was approved by the University of Szeged, Albert Szent-Györgyi Clinical Center, Regional and Institutional Human Medical Biological Research Ethics Committee (registration number: 17/2010). Patients received comprehensive information regarding the study.

\section{Results}

Serum creatinine level of the donors was $94.6 \pm 28.1 \mu \mathrm{mol} / 1$ in the ECD group and $90.8 \pm 32.1 \mu \mathrm{mol} / 1$ in the IDK group $(p=0.123)$. Cause of death of the donors and the applied perfusion solutions were not significantly different between the two groups (Table I). 
Table I. Donor data between the ECD and IDK groups

\begin{tabular}{|c|c|c|c|c|}
\hline & $\operatorname{ECD}(n=97)$ & IDK $(n=178)$ & \multirow[b]{2}{*}{$p$ value } \\
\hline & & Mean \pm SD & Mean \pm SD & \\
\hline \multicolumn{2}{|c|}{ Donor gender (women/men) } & $42 / 55$ & $82 / 96$ & 0.281 \\
\hline \multicolumn{2}{|c|}{ Donor creatinine $(\mu \mathrm{mol} / \mathrm{l})$} & $94.60 \pm 28.10$ & $90.83 \pm 32.093$ & 0.123 \\
\hline \multicolumn{2}{|c|}{ Last $24 \mathrm{~h}$ diuresis $(\mathrm{h})$} & $5.535 \pm 2.405$ & $5.689 \pm 2.086$ & 0.156 \\
\hline \multirow[t]{4}{*}{ Cases of death } & Stroke & $41(42 \%)$ & $92(52 \%)$ & 0.257 \\
\hline & Subarachnoid bleeding & $14(14 \%)$ & $33(18 \%)$ & 0.245 \\
\hline & Trauma & $17(18 \%)$ & $39(22 \%)$ & 0.067 \\
\hline & Other & $25(26 \%)$ & $14(8 \%)$ & 0.157 \\
\hline \multirow[t]{4}{*}{ Perfusion solution } & Custodiol & $61(63 \%)$ & $71(40 \%)$ & 0.267 \\
\hline & Euro collins (EC) & $27(28 \%)$ & $60(34 \%)$ & 0.138 \\
\hline & Ultra viaspan (UW) & $7(7 \%)$ & $41(23 \%)$ & 0.589 \\
\hline & $\begin{array}{l}\text { Histidine-tryptophan- } \\
\text { ketoglutarate (HTK) }\end{array}$ & $2(2 \%)$ & $6(3 \%)$ & 0.316 \\
\hline
\end{tabular}

SD: standard deviation; ECD: expanded criteria donor; IDK: ideal donor kidneys

Regarding graft function, we have concluded that 1 year after the transplantation, there were no significant differences between the ECD and IDK groups in serum creatinine levels $(p=0.20)$ and eGFR values $(p=0.15)$. On the contrary, 5 years after the transplantation, serum creatinine level (ECD: $252.3 \pm 122.8$; IDK: $171.4 \pm 93.7 \mu \mathrm{mol} / 1 ; p=0.001)$ and eGFR (ECD: $39.9 \pm 14.4$; IDK: $54.5 \pm 16.3 ; p=0.003$ ) were significantly different between the two patient groups (Table II).

Regarding morphological changes in the kidneys, the incidence of interstitial inflammation $(69 \%$ vs. $33 \% ; p=0.025)$ and tubulitis $(64 \%$ vs. $40 \% ; p=0.014)$ was significantly increased in the ECD group compared with the IDK group 1 year after the kidney transplantation. There was no significant difference in the incidence of other histological changes (such as arteriolar hyalinosis and glomerulitis) between the two groups (Table III).

Table II. Functional changes between the ECD and IDK groups

\begin{tabular}{|l|l|c|c|c|}
\hline \multicolumn{2}{|c|}{} & ECD & IDK & $p$ value \\
\hline \multirow{2}{*}{$\begin{array}{c}\text { 1 year after kidney } \\
\text { transplantation }\end{array}$} & eGFR $\left(\mathrm{ml} / \mathrm{min} / 1.73 \mathrm{~m}^{2}\right)$ & $51.06 \pm 18.52$ & $53.75 \pm 16.57$ & 0.151 \\
\cline { 2 - 6 } & serum creatinine $(\mu \mathrm{mol} / 1)$ & $145.65 \pm 63.88$ & $132.78 \pm 58.62$ & 0.200 \\
\hline \multirow{2}{*}{$\begin{array}{c}5 \text { years after kidney } \\
\text { tranplatation }\end{array}$} & eGFR $\left(\mathrm{ml} / \mathrm{min} / 1.73 \mathrm{~m}^{2}\right)$ & $\mathbf{3 9 . 9 2} \pm \mathbf{1 4 . 4 9}$ & $\mathbf{5 4 . 5 4} \pm \mathbf{1 6 . 3 2}$ & $\mathbf{0 . 0 0 3}$ \\
\cline { 2 - 6 } & serum creatinine $(\mu \mathrm{mol} / 1)$ & $\mathbf{2 5 2 . 3 6} \pm \mathbf{1 2 2 . 8 3}$ & $\mathbf{1 7 1 . 4 5} \pm \mathbf{9 3 . 7 2}$ & $\mathbf{0 . 0 0 1}$ \\
\hline
\end{tabular}

ECD: expanded criteria donor; IDK: ideal donor kidneys; eGFR: estimated glomerular filtration rate 
Table III. Banff score changes 1 year after kidney transplantation

\begin{tabular}{|c|c|c|c|c|}
\hline & & $\operatorname{ECD}(n=97)$ & IDK $(n=178)$ & $p$ value \\
\hline \multirow[t]{2}{*}{ Glomerulitis } & 0 & $38(39 \%)$ & $127(71 \%)$ & 0.347 \\
\hline & $1-3$ & $59(61 \%)$ & $51(29 \%)$ & 0.289 \\
\hline \multirow{2}{*}{$\begin{array}{l}\text { Intersitial } \\
\text { inflammation }\end{array}$} & 0 & $30(31 \%)$ & $119(67)$ & 0.745 \\
\hline & 1-3 & $67(69 \%)^{*}$ & $59(33 \%)$ & 0.025 \\
\hline \multirow[t]{2}{*}{ Tubulitis } & 0 & $35(36 \%)$ & $108(60 \%)$ & 0.934 \\
\hline & 1-3 & $62(64 \%)^{* *}$ & $70(40 \%)$ & 0.014 \\
\hline \multirow[t]{2}{*}{ Arteriola hyalinosis } & 0 & $62(64 \%)$ & $152(85 \%)$ & 0.297 \\
\hline & $1-3$ & $35(36 \%)$ & $26(15 \%)$ & 0.528 \\
\hline \multirow[t]{2}{*}{ Intimal arteritis } & 0 & $71(73 \%)$ & $114(64 \%)$ & 0.794 \\
\hline & $1-3$ & $26(27 \%)$ & $64(36 \%)$ & 0.438 \\
\hline
\end{tabular}

ECD: expanded criteria donor; IDK: ideal donor kidneys.

$* p=0.025$.

$* * p=0.014$

\section{Discussion}

Due to changing donor demographics, excessive waiting times, and the increasing disparity between organ supply and demand, the use of kidneys from ECDs has become generally accepted and increasingly common (9). In this study, we followed up kidneys from ECDs and IDK. The ratio of patients having kidney from ECDs was 35\% between January 1, 2010 and December 31,2015 . This ratio was only $12.5 \%$ in the $1990 \mathrm{~s}$. The increase in the number of ECD kidneys is partly due to the expanding of donor criteria and the fact that the number of patients in the waiting list has rapidly increased during the past few years. In the study of Ojo et al. (8), the ratio of graftectomy was $35.9 \%$ in the ECD group, whereas $24.9 \%$ in the IDK group $(p<0.001)$. Gopalakrishnan and Gourabathini (4) found that the ratio of graftectomy was $47 \%$ versus $25 \%$ in the same groups.

Like other research groups $(7,9,16)$, we also found that 1 year after the transplantation, serum creatinine and eGFR values were not significantly different between the two groups. On the other hand, 5 years after the transplantation, serum creatinine $(p=0.001)$ and eGFR ( $p=0.003$ ) were significantly different between the two groups. Regarding histopathological changes, the incidence of tubulitis and interstitial inflammation was significantly different 1 year after the transplantation between patients transplanted with ECD and IDK. This suggests that difference between morphological changes in the two groups occurs earlier than that in functional changes.

Besides differences between the ECD and IDK groups, the gradually increasing transplantation waiting lists necessitate expanding the donor criteria and the options for transplantation $(1-3,6,12,15)$. Quality of life and long-term survival of patients receiving dialysis treatment are worse compared with patients transplanted with ECD kidneys. ECD makes transplantation available for more patients and enables improving the quality of life and long-term survival for more patients. The transplantation of kidneys obtained from older donors fulfilling ECD 
definition is associated with shorter graft survival, deteriorated function, and more frequent renal delayed graft function. However, this did not increase the mortality of recipients.

\section{REFERENCES}

1. Baskin-Bey ES, Kremers W, Nyberg SL: Improving utilization of deceased donor kidneys by matching recipient and graft survival. Transplantation 82, 10-14 (2006)

2. Borda B, Szederkényi E, Szenohradszky P, Kemény É, Marofka F, Keresztes C, Lázár G: Functional and morphological changes in kidneys from marginal donors. Transplant. Proc. 44, 2139-2142 (2012)

3. Fehrman-Ekholm I, Dunér F, Brink B, Tydén G, Elinder CG: No evidence of accelerated loss of kidney function in living kidney donors: results from a cross-sectional follow-up. Transplantation 72, 444-449 (2001)

4. Gopalakrishnan G, Gourabathini SP: Expanded criteria donors kidney donor. Indian J. Urol. 23, 286-293 (2007)

5. Loupy A, Haas M, Solez K, Racusen L, Glotz D, Seron D, Nankivell BJ, Colvin RB, Afrouzian M, Akalin E, Alachkar N, Bagnasco S, Becker JU, Cornell L, Drachenberg C, Dragun D, de Kort H, Gibson IW, Kraus ES, Lefaucheur C, Legendre C, Liapis H, Muthukumar T, Nickeleit V, Orandi B, Park W, Rabant M, Randhawa P, Reed EF, Roufosse C, Seshan SV, Sis B, Singh HK, Schinstock C, Tambur A, Zeevi A, Mengel M: The Banff 2015 kidney meeting report: current challenges in rejection classification and prospects for adopting molecular pathology. Am. J. Transplant. 17, 28-41 (2017)

6. Mengel M, Gwinner W, Schwarz A, Bajeski R, Franz I, Bröcker V, Becker T, Neipp M, Klempnauer J, Haller H, Kreipe H: Infiltrates in protocol biopsies from renal allografts. Am. J. Transplant. 7, 356-365 (2007)

7. Mor E, Michowiz R, Ashkenazi T, Shabtai E, Nakache R, Eid A, Hoffman A, Mizrahi S, Shabtai M, Shapira Z: Extension of the organ pool in kidney transplantation: first year experience of the Israel Transplant Center. Isr. Med. Assoc. J. 2, 302-305 (2000)

8. Ojo AO, Hanson JA, Meier-Kriesche HU, Okechukwu CN, Wolfe RA, Leichtman AB, Agodoa LY, Kaplan B, Port FK: Survival in recipients of marginal cadaveric donor kidneys compared with other recipients and waitlisted transplant candidates. J. Am. Soc. Nephrol. 12, 589-597 (2001)

9. Persson MO, Persson NH, Källén R, Ekberg H, Hermerén G: Kidneys from marginal donors: Views of patients on informed consent. Nephrol. Dial. Transplant. 17, 1497-1502 (2002)

10. Pokorná E, Vítko S, Chadimová M, Schück O, Ekberg H: Proportion of glomerulosclerosis in procurement wedge renal biopsy cannot alone discriminate for acceptance of marginal donors. Transplantation 69, 36-43 (2000)

11. Racusen LC, Halloran PF, Solez K: Banff 2003 meeting report: new diagnostic insights and standards. Am. J. Transplant. 4, 1562-1566 (2004)

12. Remuzzi G, Cravedi P, Perna A, Dimitrov BD, Turturro M, Locatelli G, Rigotti P, Baldan N, Beatini M, Valente U, Scalamogna M, Ruggenenti P, Dual Kidney Transplant Group: Long-term outcome of renal transplantation from older donors. N. Engl. J. Med. 354, 343-352 (2006)

13. Sanchez-Fructuoso AI, Prats D, Torrente J, Pérez-Contín MJ, Fernández C, Alvarez J, Barrientos A: Renal transplantation from non-heart beating donors: a promising alternative to enlarge the donor pool. J. Am. Soc. Nephrol. 11, 350-358 (2000)

14. Satayathum S, Pisoni RL, McCullough KP, Merion RM, Wikström B, Levin N, Chen K, Wolfe RA, Goodkin DA, Piera L, Asano Y, Kurokawa K, Fukuhara S, Held PJ, Port FK: Kidney transplantation and wait-listing rates from the international Dialysis Outcomes and Practice Patterns Study (DOPPS). Kidney Int. 68, 330-337 (2005)

15. Textor SC, Taler SJ, Driscoll N, Larson TS, Gloor J, Griffin M, Cosio F, Schwab T, Prieto M, Nyberg S, Ishitani M, Stegall M: Blood pressure and renal function after kidney donation from hypertensive living donors. Transplantation 78, 276-282 (2004)

16. Toma H, Tanabe K, Tokumoto T, Shimizu T, Shimmura H: Time-dependent risk factors influencing the longterm outcome in living renal allografts: donor age is a crucial risk factor for long-term graft survival more than 5 years after transplantation. Transplantation 72, 940-947 (2001)

17. Whiting JF, Zavala EY, Alexander JW, First MR: The cost-effectiveness of transplantation with expanded donor kidneys. Transplant. Proc. 31, 1320-1321 (1999)

18. Wolfe RA, Ashby VB, Milford EL, Ojo AO, Ettenger RE, Agodoa LY, Held PJ, Port FK: Comparison of mortality in all patients on dialysis, patients on dialysis awaiting transplantation, and recipients of a first cadaveric transplant. N. Engl. J. Med. 341, 1725-1730 (1999) 